\title{
A rota do património industrial no vale do ave (norte de portugal) numa nova tendência do turismo
}

\author{
José Carlos Menezes Rodrigues*
}

Instituto de Estudos Superiores de Fafe (Portugal)

\begin{abstract}
Resumo: O turismo industrial na Europa (Reino Unido, Espanha, França e Alemanha), é emergente em Portugal, com potencialidades e constrangimentos que pode constituir-se numa plataforma de desenvolvimento cultural, social e económico, que diluirá o sentimento de fragilidade interiorizado nos cidadãos, facto consonate com os objetivos do estudo: i) reconhecer o turismo industrial como uma nova tendência; ii) avaliar o seu potencial económico-social; iii) legitimar o planeamento em turismo industrial como um elo a estabelecer com as necessidades da população local; iv) relevar a ausência de dinâmica na Rota do Património Industrial do Vale do Ave, criada em 2002. Na metodologia, enfatizamos os conceitos de património industrial e turismo industrial, as rotas, a musealização, a NP 4556/2017 - Norma de Qualidade do Turismo Industrial em Portugal; as imagens e o quadro elaborado sobre a rota finalizam os procedimentos utilizados. Nas conclusões, evidenciamos as propostas para a reativação da Rota.
\end{abstract}

Palavras-chave: Europa; Vale do Ave; Turismo industrial; Rotas; Museologia; Memórias.

The route of the industrial heritage in the vale do ave (north of portugal) in a new trend of the tourism

Abstract: The route of the industrial heritage in the Vale do Ave (north of portugal) in a new tendency of the industrial tourism in Europe (United Kingdom, Spain, France and Germany), is emerging in Portugal with potentialities and constraints that can constitute a platform for cultural, social and economic development, which will dilute the sense of internal fragility in the citizens, consonate with the objectives of the study: i) recognize industrial tourism as a new trend; (ii) assessing their economic and social potential; iii) legitimize planning in industrial tourism as a link to be established with the needs of the local population; iv) to highlight the absence of dynamics in the Industrial Heritage Route of Vale do Ave, created in 2002. In the methodology, we emphasize the concepts of industrial heritage and industrial tourism, routes, musealization, NP 4556/2017 - Quality Standard Industrial Tourism in Portugal; the images and the table drawn up on the route complete the used procedures. In the conclusions, we highlight the proposals for the reactivation of the route.

Keywords: Europe; Vale do Ave; Industrial tourism; Routes; Museology; Memoirs.

\section{Introdução}

A existência de uma Rota do Património Industrial do Vale do Ave motivou-nos para uma abordagem ao turismo industrial. Património já não é monumento, símbolo de poder, afirmação de elites ou linhagens, é imagem do Homem que, em sociedade, se eleva acima da estrita sobrevivência individual. A sua preservação é indispensável para a persistência da memória histórica desse longo caminho em que, como dizia M. Vieira Natividade, patrimonialista alcobacense, o homem fez a indústria e a indústria fez o homem (Duarte, 2013).

O desenvolvimento do turismo industrial (Jansen-Verbeke, 1999, citado por Mota, 2011: 32) depende da necessidade política de identificação cultural regional e da necessidade económica de criação de novas atividades e produtos. O potencial económico do património industrial é um forte incentivo à

Instituto de Estudos Superiores de Fafe (Portugal); E-mail: meneses.jc@gmail.com 
implementação de diversas atividades como, por exemplo, centros de informação e educação, centros de visitantes, museus, centros comerciais, alojamento turístico e facilidades desportivas.

A singularidade do turismo industrial está fortemente relacionada com a cultura e o património industrial de uma dada região, dependendo, entre outros, dos valores sociais e culturais locais e das relações que a população local estabelece com o meio. Ter a percepção do funcionamento dessas dinâmicas é um fator de sucesso para o desenvolvimento do turismo industrial (Mota, 2011: 18).

Os objetivos do estudo são: i) reconhecer o turismo industrial como uma nova tendência na Europa, particularmente, e em Portugal; ii) avaliar o seu potencial económico-social; iii) legitimar o planeamento em turismo industrial como um elo a estabelecer com as necessidades da população local; iv) relevar a ausência de dinâmica na Rota do Património Industrial do Vale do Ave, criada em 2002; v) adiantar propostas de reativação da Rota.

A metodologia estriba-se na literatura sobre o património e turismo industrial na Europa e, particularmente, na Península Ibérica; o RCAAP e a bibliografia de autores espanhóis foram a nossa fonte; enfatizamos os conceitos de património industrial e turismo industrial, as rotas, a musealização, a NP 4556/2017 - Norma de Qualidade do Turismo Industrial em Portugal; e a Rota do Património Industrial do Vale do Ave (norte de Portugal); as imagens e o quadro elaborado sobre a mesma finalizam os procedimentos utilizados.

Enfatizamos, nos blocos, o que se passa na Europa (Reino Unido, Alemanha, França e Espanha); o turismo industrial como uma nova tendência; a NP 4556/2017 - Norma de Qualidade do Turismo Industrial em Portugal; e as nossas propostas para a revitalização da Rota do Património Industrial do Vale do Ave.

Concluímos que a Rota do Património Industrial do Vale do Ave terá oportunidade de se reinventar se os dez municípios envolvidos - além das entidades vocacionados para o efeito e das populações locais -, manifestarem uma vontade irreversível de proporcionar à região uma relevante mais-valia económica, social e cultural.

\section{Turismo industrial: uma nova tendência}

Os meados da década de 1970 (Abad, 2004: 9-10) são uma época de uma crise económica profunda com o encerramento de fábricas generalizado; a atração por instalações industriais, especialmente as abandonadas no espaço urbano, as chaminés entre edifícios, as máquinas em desuso e os terrenos criaram um forte impacto sobre o cidadão, as autoridades locais e o investigador dos chamados países de industrialização antiga. Sendo seletivo o processo de industrialização "tal afeta ainda mais o caráter patrimonial de seus restos materiais porque eles identificam como emblema as zonas ou cidades nas quais a primeira Revolução Industrial ocorreu". O património industrial é o mais jovem de todos os patrimónios porque abrange um conjunto de estruturas, peças e máquinas que foram usadas, em muitos casos, até há bem pouco tempo.

Em Portugal, o conceito de património industrial remonta à segunda metade do século XX; o desenvolvimento da arqueologia industrial data dos finais da década de 1970. Se a memória social se havia constituído e identificado em torno de valores estéticos e artísticos, desenvolvendo o conceito de património, "a emergência de vestígios de uma cultura técnica qualificados como património veio lançar um novo paradigma na área cultural (Matos, Ribeiro \& Santos, 2003: 21)."

O turismo industrial valoriza a cultura e a sociedade, "unificando los patrimonios industrial, natural y cultural (Cuadrado, 2006, citado por Prat \& Valiente, 2012: 85); reafirmando la identidad de la comunidad (Álvarez, 2003, citado por Prat \& Valiente, 2012: 85) y la continuidade de sus antecedentes industriales, técnicos, económicos, sociales y culturales (Gómez, 2002; Bergeron, 2003, citado por Prat \& Valiente, 2012: 85), y configurando el patrimonio industrial como un elemento básico de los paisajes $y$ de la cultura del territorio (Abad, 2004, citado por Prat \& Valiente, 2012: 85). É uma forma de relevar o vínculo social com o território, englobando elementos interrrelacionados: território, património industrial e tarefas e costumes próprios da vida local, bem como todas las atividades relacionadas diretamente com o património e com a sustentabilidade do destino (Lee, 2005; Miller, 2010, citado por Prat \& Valiente, 2012: 86).

O turismo do património industrial - um dos sinónimos de turismo industrial - é um fenómeno dinamizador do território na medida em que as exigências atuais dos turistas com poder aquisitivo e disponibilidade de tempo livre converte-os em grandes consumidores de bens e serviços, aumentando as exigências dos gestores turísticos que têm de adotar novas estratégias de atração dos visitantes 
para que o ócio e a cultura sejam valores a contemplar (Borja, Jiménez y Sevilla, 2005, citado por Prat \& Valiente, 2012: 84-85).

"como una alternativa para el desarrollo de territorios industriales deprimidos social y económicamente (al estar afectados por el cierre y el abandono de la actividad productiva)" ou "como una oferta complementaria que ayude a otros turismos más tradicionales y consolidados, como el de sol y playa".

Frew (2000, citado por Mota, 2011: 8) regista uma justaposição entre turismo industrial e turismo educacional; exemplo: uma visita de estudo a uma unidade fabril realizada no âmbito de um projeto universitário sobre métodos de produção. A associação com o turismo cultural resulta da entrada do turista no mundo cultural imaterial, que inclui demonstrações de vivências, hábitos do quotidiano, relações pessoais, crenças e rituais presentes na zona visitada. Temos turismo de património industrial quando a visita incide em equipamentos industriais já não em laboração; quando já não é a que despoletou a sua construção primitiva, trata-se do turismo de património industrial - associação entre o turismo industrial e o turismo de património (subclasse do turismo cultural) - atividade turística que engloba visitas a monumentos antigos, escavações arqueológicas e outros locais de interesse histórico (Wall \& Mathieson, 2006, citado por Mota, 2011: 8). Há ainda a relação entre o turismo industrial e o agroturismo - que proporciona aos turistas atividades agrícolas diversificadas (Kizos \& Iosifides, 2007, citado por Mota, 2011.

Temos turismo industrial quando se : i) prevê o conhecimento da identidade cultural industrial da região, pela inventariação dos recursos materiais e imateriais; ii) promove a proteção, a valorização e a revivescência da cultura e património industrial, de artes e de produtos tradicionais endémicos, incentivando a sua manutenção; iii) enfatiza a autenticidade cultural do produto turístico industrial através do respeito pela unicidade cultural do local; iv) fomenta a criação de postos de trabalho: guias turísticos, rececionistas (emprego direto), artesãos, comerciantes locais, gestores hoteleiros, animadores turísticos, planeadores, marketeers (emprego indireto), nos setores da construção civil, da engenharia, da arquitetura, da jardinagem, da informática, da banca, do comércio e de serviços gerais (emprego induzido), entre tantos outros; v) incentiva o empowerment da população local no sentido de serem elementos ativos no desenvolvimento do produto turístico industrial e de terem autonomia e iniciativa empreendedora; vi) prevê o aumento de receitas para as empresas que integram o produto turístico industrial e restantes intervenientes; vii) diligencia a melhoria de infraestruturas, de vias rodoviárias e pistas clicáveis; viii) concorre para a diversificação da oferta turística da região, propiciando o aumento do tempo de permanência do turista; ix) contribui para a diminuição da sazonalidade que caracteriza a atividade turística; $\mathrm{x}$ ) incentiva a inclusão de empresas locais no projeto para o estímulo da economia da região (Mota, 2011: 94-95).

O turismo industrial é uma nova tendência turística (Abad (2004: 29-30) mediante itinerários, museus e vestígios; esta aproximação marca uma nova geografia carregada de simbolismo e monumentos industriais: um património que serve de atração turística e de recurso para um desenvolvimento económico e de elo às inovações de outros tempos. Esta nova tendência entronca nos valores do património industrial exarados pela The International Committee for the Conservation of the Industrial Heritage (TICCIH, 2003, citado por Mota, 2011: 26-27)

“(...) As razões que justificam a proteção do património industrial (...) não [decorrem] da singularidade de quaisquer sítios excepcionais. (...) reveste-se de um valor social que é parte do registo da vida de homens e mulheres comuns (...) o património industrial apresenta-se, ainda, com valor científico e tecnológico, para além do carácter estético associado à qualidade da sua arquitetura, do seu design ou do seu planeamento."

\section{Para uma geografia do património industrial}

\subsection{Na Europa}

A explosão da consciência da conservação e salvaguarda dá-se nos anos 70 do século XX, estendendo-se aos países nórdicos da Europa, Estados Unidos e Canadá. Em França, a zona mineira de Le Creusot, na Borgonha, originou o Museo de la Mineria de Blanzy, englobado dentro do ecomuseu da comunidade urbana de Le Creusot-Montceau-Les Mines, iniciativa pioneira na Europa. Em Espanha, as iniciativas são mais recentes, nos finais do século XX e início do século XXI (Álvarez, 2017: 660). 
Há exemplos bem conhecidos ao nível da Europa: no Reino Unido, visitas a destilarias de whisky na Escócia, à fábrica de chocolate da Cadbury, na Inglaterra, com o símbolo icónico do passado industrial britânico fundado em 1973: Ironbridge Gorge Museum; no mesmo ano, cria-se o Ecomusée Le Creusot, sob a responsabilidade do TICCH - The Interntional Comittee for the Conservation of the Industrial Heritage -, que define Património Industrial (Vieira e Lacerda, 2010: 11); à mina de carvão Big Pit, no País de Gales. Já ganhou importância na Bélgica, na Austrália, na China, em Israel, nos EUA.

Em 1997, o primeiro bem de natureza industrial a integrar a lista da UNESCO foi Hallstatt-Dachstein salzKammergut Cultural Landscape, exploração de sal na Áustria (Vieira e Lacerda, 2010: 11). A lista de lugares ou monumentos Património da Humanidade (Colt, 1999: 150-151) incluía, em 1999, um número reduzido do tipo industrial, todos na Europa: Alemanha, Finlândia, Fança, Polónia, Suécia, Áustria e Reino Unido. A Espanha, na altura, tinha 29 monumentos históricos e nenhum de carácter industrial. Em cerca de três décadas, a situação foi mudando em Espanha, no Reino Unido, na Alemanha, na França ou na Itália.

Atualmente, na lista do Património Mundial, na área do património industrial (http://whc.unesco. org/) figuram os países e respetivos quantitativos: Alemanha (4); Áustria (2); Bélgica (2); Bolívia (1); Brasil (2); Chile (2); Cuba (1); Eslováquia (1); Espanha (2); Finlândia (1); França (3); Índia (1); Itália (1); México (3); Noruega (1); Países Baixos (2); Polónia (2); Portugal (2 - 1996 - Centro Histórico do Porto e 2001 - Região Vitivinícola do Alto Douro); Reino Unido da Grã-bretanha e Irlanda do Norte (7); Suécia (4).

Abad (2004) releva o tipo patrimonial ou histórico que incide nas fábricas abandonadas, com reutilização museológica ou com instalações de algum centro artísticos ou interpretativo; incluem-se também peças soltas (máquinas de vapor), territórios mais ou menos amplos de outras fases da industrialização; é um turismo basicamente cultural. $E$ um turismo mais importante no norte da Europa devido à sua menor riqueza artística que no sul do continente. Por esta razão, Alemanha, Suécia, Finlândia, Reino Unido, Bélgica, reconheceram com entusiasmo os testemunhos da sua industrialização como um importante recurso turístico; na Espanha, França, Itália ou Portugal o interesse foi suscitado mais tardiamente, mas também "mais acelerado logrando recuperar já bastantes elementos principais do seu património industrial."

\subsection{As rotas industriais}

Abad (2004: 21-25) evidencia a mais-valia das que inserem o turismo industrial: i) Rotas urbanas - a cidade é o cenário por excelência da Revolução Industrial; no séc. XIX, a fábrica instala-se onde é possível absorver mão-de-obra abundante com salários baixos; alguns desses edifícios reconverteram-se em espaços culturais, vivendas e modernas sedes de empresas; Barcelona e Manchester são exemplos. ii) Rotas comarcais: na Catalunha há uma variedade de elementos que se aproximam do conceito de colónia industrial, com a possibilidade de percurso de horas ao longo do rio Ter. iii) Rotas regionais: um dos melhores exemplos é a Rota do Património Industrial da região alemã da Renânia-Vestefália; todos os pontos são servidos por meios de transporte público; a rota tem vários museus, enclaves panorâmicos e fábrica importante, com suficiente informação específica e cartográfica.

"Los edificios industriales son una auténtica seña de identidad arquitectónica para la región y los nuevos usos se han enfrentado a problemas de difícil solución (..) la zona se ha convertido en una de las regiones europeas que mejor há sabido orientar la conservación y la explotación turística de un riquísimo património industrial, superar la depresión económica y regenerar un paisaje desolado por la ruina y el abandono (Collinet, 2002: 65, citado por Abad, 2004: 24).”

Aquela região alemã integra-se na Rota Europeia de Património Industrial (ERIH); até 2004, a rede desenvolveu-se através de regiões específicas entre a Grã-Bretanha, Países Baixos e Alemanha, criando-se as bases de "um autêntico mercado turístico europeu de património industrial, assim como estreitar os pontos de referência da rede com os seus organismos turísticos regionais e nacionais"; iv) Rotas temáticas: são rotas de carácter comarcal e regional, não se apresentando separadas, porque têm a peculiaridade de se relacionarem com o mesmo setor industrial. Exemplos: rota mineira (carvão) de Rhin, na Alemanha; rota da lã, em Piemonte, Itália; na Catalunha, a rota do papel e a rota do minério.

\subsection{As rotas da lĩ}

Estas rotas merecem um destaque especial (http://www.rutasdelalana.eu/mapa/mapa.jsp.htm) por, há cerca de 12.000 anos, vestirem a espécie humana. A ovelha merina é descendente das ovelhas trazidas 
pelos árabes para a Península Ibérica, nos inícios do século XIV, desde África; até ao século XVII, as leis castelhanas não permitiram a sua exportação; mas em 1789 chegam à colónia inglesa de Sydney.

Em Portugal, A Rota da Lã - Translana (http://www.centerofportugal.com/pt/a-rota-da-la-translana/) é um projeto de 2007, abrangendo as rotas laneiras das regiões da Beira Interior (distritos de Castelo Branco e Guarda) e parte da Estremadura espanhola (Comarca de Tajo-Salor-Almonte) que permitiu identificar mais de mil locais de interesse histórico, cultural e antropológico para a história dos lanifícios. Dois museus marcam o início e o fim desta Rota da Lã: a rota parte do Lavadero de Lanas de los Barruecos (Malpartida de Cáceres), onde se encontra sediado o Museu Vostell-Malpartida, que, desde o século XVIII, serviu para a tosquia dos rebanhos e, na Primavera, por ali passavam rumo às pastagens do Norte e lavagem das lãs merinas. Este grande edifício ligado à produção laneira pré-industrial da região de Cáceres abastecia diversas regiões da Europa, e era aqui que almocreves e comerciantes de lã da Beira vinham, sazonalmente, adquirir a matéria-prima para as fábricas da Covilhã. Acerca da Europa, a rota vai (http://www.rutasdelalana.eu/mapa/mapa.jsp.htm) de Espanha à República Checa.

\subsection{Itinerários Culturais do Conselho da Europa e Rota Europeia}

Dos Itinerários Culturais do Conselho da Europa (Instituto Europeu dos Itinerários Culturais), (http:// www.culture-routes.lu/php/fo_index.php?) destacamos: i) 2004. Rota do Ferro nos Pirenéus [Andorra, Espanha (Catalunha e País Basco), França (Midi-Pirinéus, Aquitânia)]; ii) 2012. Rota Europeia da Cerâmica (Alemanha, Espanha, França, Itália, Países Baixos, Portugal, Reino Unido e Turquia); iii) O projeto Rotas do Volfrâmio na Europa - Memória dos Homens e Património Industrial visou a criação de uma rota turística cultural, de âmbito europeu, com vista à valorização e preservação do património material e imaterial. O ISCET (Instituto Superior de Ciências Empresariais e do Turismo), com ações iniciadas em 2010-2011, propôs-se entregar o dossiê para aprovação, em setembro de 2014, como Itinerário do Conselho da Europa: com a II Guerra Mundial, as minas são praticamente dominadas por alemães e ingleses que, em Portugal, convivem pacificamente. O volfrâmio (tungsténio), por ser essencial à construção de material bélico, vai tornar-se um recurso muito disputado, tendo sido sabiamente utilizado pela ditadura de Oliveira Salazar, mantendo a neutralidade de Portugal face ao conflito.

Estão referenciadas minas em Arouca, Bragança, Castro Daire, Fundão, Montalegre, Sabrosa, S. Pedro do Sul, Terras do Bouro, Vimioso, estendendo-se à Galiza, à França, às Minas da Cornualha (Inglaterra), à Alemanha, à Suécia e à República Checa (www.minhaterra.pt/rotas-do-volframio-na-europa-memoria-dos-homens-e-patrimonio-industrial.T11624.php).

O European Route of Industrial Heritage (European Year of Cultural Heritage, 2018) é um projeto de 1999, com mais de 150 membros de 17 países europeus; 66 pontos-âncora em 17 países; 830 sítios industriais/museus em 29 países; 10 rotas temáticas, com um total de 575 sítios, em 4 países; rotas regionais: 10 rotas (com um total de 188 sítios) em 4 países; marketing em rede; visitantes: mais de 10 milhões por ano; quotização anual: ponto-âncora - €500; sítios individuais: €100; membros institucionais: $€ 500$; individuais: $€ 100$.

\subsection{Na Espanha}

A Rede de Turismo Industrial da Catalunha (2016), com rotas temáticas do património mineiro, fornece vantagens aos seus aderentes: receber um boletim com informação sobre as mais recentes iniciativas de turismo industrial promovidas pela Rede; informações sobre ofertas especiais; dispor gratuitamente do cartão da Rede; descontos especiais em museus e centros de interpretação; descontos em passeios e outras atividades; ofertas e promoções exclusivas de alojamento em hotéis, parques de campismo, casas de turismo rural; desconto especial para serviços de restauração, lojas e outros serviços turísticos e culturais; propostas destinadas exclusivamente aos membros do Clube. A Associação de Municípios La Xatic criou a primeira central de reservas da Europa (http://www.xatic.cat). A RETI (Rede Espanhola de Turismo Industrial) (Cordeiro, 2014) oferece às instituições/empresas: adesão a uma marca turística que promove a excelência de serviço reconhecida com o distintivo Produto RETI, oficialmente apoiada pelo Turespaña; a gestão automatizada das suas visitas e reservas através do portal www.turismoindustrial.es; a comercialização da sua oferta, com sistema de pagamento online das visitas; a visibilidade e a publicidade da sua instituição ou empresa através de uma rede nacional especializada; uma assistência especificada, adaptada a cada situação, para gerir com sucesso e com total flexibilidade as suas visitas. Ao visitante, as instituições/empresas oferecem: visitas guiadas com horários e condições de visita predeterminados; a descoberta do saber-fazer industrial, do passado, 
presente e futuro; a garantia de rigorosos compromissos de serviço para garantir visitas de qualidade; cidades inscritas: A Coruña, Alicante, Cadiz, Murcia, Segovia, Sevilla, Toledo e Almadén.

\subsection{Em Portugal}

A APPI (Associação Portuguesa para o Património Industrial) (http://www.museudaindustriatextil. org/appi/patrimonio-nacional.php) - contém o património industrial

classificado no país (por ordem alfabética dos distritos e data de classificação, incluindo ainda a identificação do autor, a data da construção e a localização do imóvel por freguesia e concelho, tipo de classificação e respetivo suporte legislativo).

A DGPC (Direção Geral do Património Cultural) (http://www.patrimoniocultural.pt/pt/patrimonio/ itinerarios/industrial/) apresenta as manufaturas, as indústrias, as estruturas sociais associadas e as obras públicas/infra-estruturas - da Fábrica de Tecidos de Sedas (séc. XVIII), Lisboa, à Estação do Caminho-de-ferro de S. Bento (séc. XIX-XX), Porto.

\subsection{A musealização}

Faz-se prevalecer os museus sobre fábricas abandonadas, os centros culturais abertos onde antes palpitavam as velhas máquinas de vapor, os centros comerciais ou de interpretação (Abad, 2004: 31).

O interesse pela musealização industrial terá começado em Inglaterra, como afirma Ávarez (2017: 659-660), com os restos da Revolução Industrial (segunda edição do século XVIII), em 1962, a portaria neodórica de uma estação de ferrocarril em Londres, na Estação Euston, construída em 1835-1839. Estavam criadas as condições para a Grã-Bretanha avançar com o Council British Archaeology que criou, em 1959, um comité especial para a preservação dos monumentos industriais - The National Survey of Industrial Monuments.

As novas perspetivas de musealização do património industrial e a sua influência em Portugal (1990-2010) é tema de Matos e Sampaio (2014: 98-100). Na década de 80 do século XX, fundam-se as primeiras associações na defesa e no estudo do património industrial: a AAIRL (Associação de Arqueologia Industrial da Região de Lisboa), criada em 1980 - que deu origem à APAI (Associação Portuguesa de Arqueologia Industrial) -, e a APOREM (Associação Portuguesa de Empresas com Museus), nascida em 1992, com o objetivo de preservar o património e a memória das empresas e apresentá-las em espaços museológicos abertos à comunidade.

O movimento da Nova Musealização (1971-1974), que origina o conceito de ecomuseu, colocado em prática, pela primeira vez, na comunidade de Le Reusot/Monteceau-Les-Olives, em França, vai encontrar Portugal, na década de 80 do século XX, num processo de desindustrialização, que obrigou a repensar o território e a criação de novos espaços culturais e museológicos, associados às mais-valias da "marca indústria" como fator estratégico no desenvolvimento económico e turístico de uma cidade ou região: é a "museologia industrial", defendendo-se a proximidade do museu com a comunidade, a preservação de património relativo ao trabalho e ao quotidiano, a interatividade nos museus e a sua função pedagógica (Mendes, 2013, citado por Matos e Sampaio (2014: 99-100).

\section{Uma exigência e uma estratégia: NP 4556/2017 - Norma de Qualidade do Turismo Industrial}

Se a França, a Alemanha e a Espanha (Cordeiro, 2017: 18) estão num processo normativo bastante evoluído (os serviços de turismo certificado no património industrial certificado abriram excelentes perspetivas para o incremento da sua comercialização, em 2012), Portugal está a dar passos seguros para o efeito.

Em 2018 (Diário de Notícias, 05 de abril) anuncia-se a NP 4556/2017 - Norma de Qualidade do Turismo Industrial - apresentada em São João da Madeira, no âmbito do II Encontro da Rede Portuguesa de Turismo Industrial, explanando o Instituto Português de Qualidade que o processo foi iniciado por iniciativa do município de São João da Madeira, que, sendo pioneiro no setor, reuniu para o efeito "o conjunto nacional das entidades mais representativas e relevantes" de um segmento de nicho, em fase de afirmação em Portugal, mas já "um fenómeno crescente em todo o mundo":

Aquele jornal destacava ainda Turismo Industrial avança para constituição de rede oficial do setor, com as dezasseis entidades que participaram no encontro de S. J. da Madeira a avançarem para o processo de constituição de uma rede nacional official - incluindo a oficialização e regulamentação da estrutura - representado, a título de exemplo, pela Rotas da Filigrana de Gondomar, Rota do Têxtil de Famalicão, Rota da Eletricidade de Seia, Rota do Mármore de Anticlinal de Estremoz, os Circuitos do Setor Vidreiro da Marinha Grande e a futura Rota do Móvel de Paços de Ferreira. S. J. 
da Madeira ficaria como coordenador do grupo de trabalho para o levantamento das necessidades para criação formal da Rede Portuguesa de Turismo Industrial. Uma das tarefas seria a dinamização dos processos de certificação ao abrigo da nova Norma de Qualidade do Turismo Industrial - NP $4556 / 2017$.

A NP 4556/2017 visa uniformizar procedimentos e serviços incididentes na qualidade para o Turismo Industrial, nas vertentes de Indústria Viva e do Património Industrial, experiências que se relacionam com os produtos e os processos de produção e, ou, com a memória histórica e cultural dos mesmos (Turismo de Portugal. Business, 2018).

Cordeiro (2017: 11) aborda os Circuitos pelo Património Industrial de S. João da Madeira como exemplos para outros municípios, como o de Guimarães, que criara, há pouco tempo, um projeto de turismo industrial - Guimarães Marca -, associando o prestígio da história da Cidade à atividade económica que caracterizou o território do Ave; pretendia-se promover, turisticamente, o património industrial e empresarial do concelho, em articulação com parcerias de empresas. Eis uma questão fundamental para a Rota do Património Industrial do Vale do Ave que vê sair um dos seus municípios, sinal de que esta Rota foi criada sem que os seus proponentes (ADRAVE - Associação Desenvolviemtno Região Vale do Ave - e oito municípios, chegando a dez, posteriormente) pouco mais fizessem que a sua criação. Incluímos os investigadores que, inicialmente, foram seus prosélitos...

A criação de uma Organização Responsável (OR), com pequenas entidades públicas e privadas, não havendo distinções na natureza pública ou privada das organizações de turismo industrial, no produto ou serviço, no tamanho e no setor, é vital para o desenvolvimento do turismo industrial (Cordeiro, 2017: 9).

\section{A Rota do Património Industrial do Vale do Ave}

Na paisagem do Ave (Silva, 2014:142-143), são encontrados alguns castros de um universo de cerca de 7000 do Noroeste Peninsular, um legado criado durante o primeiro milénio aC, no período anterior à chegada dos romanos, com elevada importância científica e turística, que fazem parte Rota dos Castros do Noroeste. No âmbito religioso, surge a integração de partes do território do Ave nos Caminhos de Santiago. A título de exemplo, apresentam-se: o caminho de Celanova (que abrange Santo Tirso, Guimarães, Briteiros, Braga, São Frutuoso de Montélios, Prado, Ponte de Lima, Ponte da Barca, Arcos de Valdevez, Lindoso e Madalena), o caminho de Lamego (que abrange Amarante, Felgueiras, Guimarães e Braga), o caminho de Sé a Sé (abrangendo a Sé do Porto, Leça do Balio, Santiago de Bougado, Santiago de Antas, Santiago de Gavião e Santiago da Cruz e Sé de Braga) e o caminho de Bustelo, que passa por Vizela, já marcado em 2014. A estes valores culturais aditamos o património industrial - mediante a rota estabelecida em 2002 pela ADRAVE.

O aparecimento de indústrias tradicionais na bacia hidrográfica do rio Ave vem reforçar a ideia da água constituir um recurso fundamental no desenvolvimento das suas atividades, principalmente no que respeita à utilização nos diferentes processos de produção existentes, resultando da necessidade que:

“(...) os empresários locais tiveram em diversificar o tecido industrial regional, procurando novos nichos de mercado e, por outro lado, teve também como efeito o agravamento das condições hidrológicas e ambientais (Costa, 2010:11)."

Nos últimos séculos, o rio Ave e seus afluentes marcaram, de forma singular, a implantação industrial, o que se relaciona com as vantagens associadas às facilidades hídricas para a produção de_energia e o abastecimento de água nas diferentes fases dos processos industriais em que esta é utilizada.

Uma das unidades fabris mais importantes na região foi a Fábrica de Fiação do Rio Vizela que, em 1845, instalou-se em Santo Tirso. O marco simbólico do têxtil no rio Ave situa-se no concelho de V. N. de Famalicão, com a instalação da Sampaio, Ferreira \& Companhia, em Riba de Ave; outras fábricas aparecem no início do século XX, aproveitando a força motriz das águas do rio Ave. A especificidade da indústria têxtil foi clara ao longo do todo o século XX, não só pelo peso que representou no conjunto do setor secundário, como na sua especialização ligada à fiação e ao tecido; concentrada, tendencialmente, no Médio Ave, tem uma expressão ao nível de toda a bacia; é ainda fundamental o conforto espacial que a água permitiu, a nível local, na ligação a outras atividades especializadas, como foram os casos dos curtumes e da indústria de papel (Costa, 2010: 1; 3-5).

O linho foi uma marca duradoura de Guimarães e seus arredores, mas: 
“(...) o algodão sobreveio bastante cedo na zona mais vasta do Vale do Ave, percepcionando-se o seu fabrico, ainda que sob a forma de tecido misto com o linho, com a seda ou a lã desde os inícios do século XIX, pelo menos (Alves, 2002:372)."

Rapidamente o algodão ganhou um papel determinante, por via das inovações revolucionárias do trabalho industrial, que o transformam num produto popular, de baixo custo (os preços do algodão em rama baixaram gradualmente durante o século XIX, devido à introdução de máquinas e ao alargamento das áreas de cultura nos Estados Unidos), com facilidade de transformação e de variedade no produto final, que subverte costumes de vestuário pelo mundo inteiro, através das chitas, dos cotins, das flanelas e de outros tipos de tecidos.

O algodão, sedimentado no Porto, com caminho facilitado pela função de plataforma de comércio colonial que aquela Cidade representava, vai subir para as zonas periféricas, atingindo nesse alastramento algumas áreas do Vale do Ave. Para os publicistas " $a$ indústria do algodão, apesar de trabalhar sobre matéria-prima exótica, encontrou entre nós condições de vida muito especiais (Seabra, 1904: 16, citado por Alves, 2002: 372)."

O inquérito industrial de 1890 fornece uma imagem precisa sobre o setor do algodão, no distrito de Braga, vislumbrada pela referência a numerosas unidades de tecelagem para os concelhos envolventes do Ave e para o curso do rio Cávado. Há unidades referenciadas nominalmente e com a respetiva localização para as situações em que se verificassem oito ou mais operários e dados agregados para as unidades que tivessem menos de oito trabalhadores, embora não susceptíveis de quantificação final quanto ao número global de trabalhadores, devido ao facto de numerosas unidades deste tipo não terem dado informações relativas a este quesito (Alves, 2002:376).

São ambíguos em termos de dimensão, bastando dizer que as duas referências a Fafe dizem respeito às fábricas do Bugio (empreendedorismo de um brasileiro torna-viagem, José Florêncio Soares), então com 180 operários, e do Ferro (CFF de Fafe), com 339 operários, dispondo já de energias hidráulicas e de máquinas a vapor, as quais não têm comparação com as dimensões reduzidas das restantes unidades. Mas a imagem dada pelo inquérito é suficiente para mostrar que era na bacia do Ave, particularmente nas freguesias em torno do rio Ave e do seu afluente Selho, que se conglomerava a atividade de fiar e tecer.

\section{Figura 1: Localização da RPI}

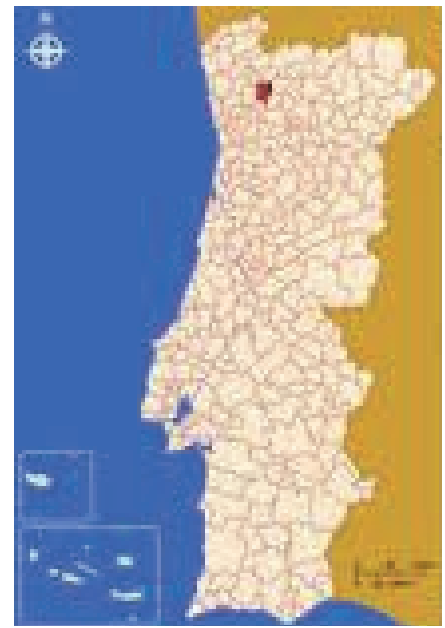

Fonte: http://www.cim-ave.pt/index.php/quem-somos/municipios

O desenvolvimento do projeto da Rota do Património Industrial do Vale do Ave (Cleto \& Faro, 2002: 148-152) permitiu detetar que grande parte dos espaços visitados encontravam-se bastante degradados, não sendo possível integrá-los. O estudo considerou extremamente válido o esforço 
de identificação e caracterização dos imóveis realizado pelas autarquias envolvidas. A intervenção museográfica, ao longo da Rota, em alguns dos espaços, tornaria possível a penetração no local e uma melhor compreensão da região que a alberga. Os mecanismos de identificação e valorização deverão ser lidos numa perspetiva de requalificação do Vale do Ave, da relação do Homem com o espaço que ocupa, gerindo os recursos que a natureza disponibiliza e ditando a sua dinâmica de futuro. Concordamos com Alves (2004, 8-9): o património industrial do Vale do Ave não pode basear-se apenas no resíduo constituído por estruturas desativadas, em ruínas de uma paisagem que continua viva; não pode estruturar-se sobre aquilo que alguns designam de baldios patrimoniais, tendo em conta as ruínas fabris, mas terá de se configurar como o retrato histórico de uma região industrial, "revelando a patine do tempo que, pelo amadurecimento, pode ajudar a conferir qualidade e prestígio à empresa histórica, o verdadeiro pulmão do espaço social da indústria." Mas numa rota dinâmica, não a que percecionamos na atualidade...

A indústria do Vale do Ave, desde 1845 (www.rotanoave.com/pt/Homepage.aspx) está marcada por critérios como inovação e empreendedorismo, que lhe conferiram um papel importante no palco do desenvolvimento nacional, sendo uma das zonas mais industrializadas do país. Quando a indústria têxtil era predominantemente dominada pela produção familiar de linho, surge o conceito de fábrica e altera-se a matéria-prima por algodão. Surgiram aglomerados fabris que albergaram em tempos áureos milhares de operários. O Vale do Ave, predominantemente têxtil, viu, no entanto, subsistirem outras indústrias, complementares ou completamente díspares.

O projeto foi promovido pela ADRAVE, em 2002, (www.rotanoave.com/pt/Homepage.aspx), passando a ter em mãos uma verdadeira teia a urdir -, com objetivos: i) situar a indústria do Vale do Ave numa perpetiva histórica, sociológica, antropológica e arquitetónica; ii) criar uma rota com percursos temáticos salientando a importância do rio Ave; iii) preservar o património pré-industrial e industrial, evocando-se a diversidade e a qualidade das estruturas arquitetónicas existentes (Costa, 2010: 364: 365). A Rota foi formada por oito concelhos (Fafe, Guimarães, Póvoa de Lanhoso, Santo Tirso, Trofa, Vieira do Minho, Vila Nova de Famalicão e Vizela, percorrendo 24 unidades industriais e pré-industriais distribuídas por sub-rotas na compreensão dos processos de industrialização do Vale do Ave: i) rio e mecanismos da água (da energia hidráulica à energia elétrica); ii) espaços de produção (variedade e complexidade); iii) paisagem industrial (modernização e persistências locais). Atualmente, desenha-se com dez polos (Figs. 2 e 3), com a entrada de Cabeceiras de Basto e de Mondim de Basto.

\section{Figura 2: Rota do Património Industrial do Vale do Ave}

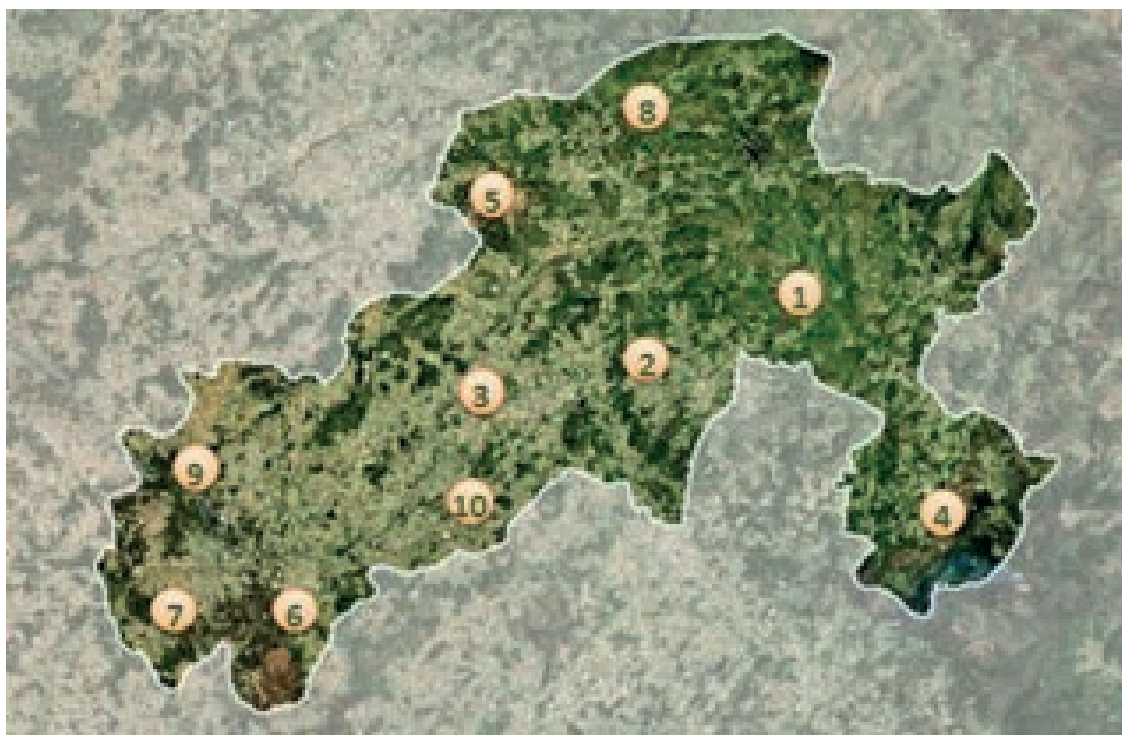

Fonte: http://www.cim-ave.pt/index.php/quem-somos/municipios 
Quadro 1: Polos do Vale do Ave e CIM do Ave

\begin{tabular}{|c|c|c|c|c|}
\hline $\begin{array}{l}\text { Polos iniciais do } \\
\text { projeto }\end{array}$ & Conteúdos & Polos atuais & $\begin{array}{l}\text { Conteúdos a } \\
\text { acrescentar }\end{array}$ & $\begin{array}{c}\text { CIM do } \\
\text { AVE (Comunidade } \\
\text { Intermunicipal do } \\
\text { Ave) }\end{array}$ \\
\hline \multirow[t]{3}{*}{ 1. Fafe } & $\begin{array}{l}\text { Central Hidroelétrica } \\
\text { de Santa Rita }\end{array}$ & \multirow[t]{3}{*}{ 1. Fafe } & \multirow{3}{*}{$\begin{array}{l}\text { Museu do Moinho } \\
\text { e do Povo de } \\
\text { Aboim (2009) }\end{array}$} & \multirow[t]{3}{*}{ Fafe } \\
\hline & $\begin{array}{l}\text { Companhia de Fiação e } \\
\text { Tecidos do Ferro }\end{array}$ & & & \\
\hline & $\begin{array}{l}\text { Fábrica de Fiação de } \\
\text { Algodão do Bugio }\end{array}$ & & & \\
\hline \multirow[t]{2}{*}{ 2. Guimarães } & Cutipol & \multirow[t]{2}{*}{ 2. Guimarães } & \multirow[t]{2}{*}{ Casa da Memória } & \multirow[t]{2}{*}{ Guimarães } \\
\hline & Curtumes & & & \\
\hline \multirow{2}{*}{$\begin{array}{c}\text { 3. Póvoa de } \\
\text { Lanhoso } \\
\end{array}$} & Central do Ermal & \multirow{2}{*}{$\begin{array}{l}\text { 3. Póvoa de } \\
\text { Lanhoso }\end{array}$} & & Póvoa de Lanhoso \\
\hline & $\begin{array}{l}\text { Museu do Ouro de } \\
\text { Travassos }\end{array}$ & & & \\
\hline \multirow[t]{3}{*}{ 4. Santo Tirso } & Arcotêxteis & 4. Santo Tirso & & \\
\hline & $\begin{array}{l}\text { Fábrica de Fiação e } \\
\text { Tecidos de Santo Tirso }\end{array}$ & & & \\
\hline & $\begin{array}{l}\text { Fábrica de Fiação e } \\
\text { Tecidos Rio Vizela }\end{array}$ & & & \\
\hline \multirow[t]{2}{*}{ 5. Trofa } & $\begin{array}{l}\text { Antiga Estação de } \\
\text { Comboios da Trofa }\end{array}$ & \multirow[t]{2}{*}{ 5.Trofa } & & \\
\hline & $\begin{array}{l}\text { Paulino Ferreira \& } \\
\text { Filhos, Lda. }\end{array}$ & & & \\
\hline 6. Vieira do Minho & $\begin{array}{l}\text { Barragem de } \\
\text { Guilhofrei }\end{array}$ & $\begin{array}{l}\text { 6. Vieira do } \\
\text { Minho }\end{array}$ & & Vieira do Minho \\
\hline $\begin{array}{l}\text { 7. Vila Nova de } \\
\text { Famalicão }\end{array}$ & $\begin{array}{l}\text { Museu da Indústria } \\
\text { Têxtil da Bacia do Ave } \\
\text { Sampaio Ferreira } \\
\text { Regularfama } \\
\text { Museu Ferroviário de } \\
\text { Lousado }\end{array}$ & $\begin{array}{l}\text { 7. Vila } \\
\text { Nova de } \\
\text { Famalicão }\end{array}$ & & $\begin{array}{l}\text { Vila Nova de } \\
\text { Famalicão }\end{array}$ \\
\hline \multirow[t]{3}{*}{ 8. Vizela } & Termas de Vizela & 8.Vizela & & Vizela \\
\hline & $\begin{array}{l}\text { Museu de Terras de } \\
\text { Basto }\end{array}$ & $\begin{array}{l}\text { 9. Cabeceiras } \\
\text { de Basto }\end{array}$ & $\begin{array}{l}\text { Casa do Tempo } \\
\text { (2013) }\end{array}$ & Cabeceiras de Basto \\
\hline & $\begin{array}{l}\text { Museu Municipal de } \\
\text { Mondim de Basto }\end{array}$ & $\begin{array}{l}\text { 10. Mondim } \\
\text { de Basto }\end{array}$ & & Mondim de Basto \\
\hline
\end{tabular}

Fonte: Elaboração própria

Seis concelhos são comuns ao projeto inicial e à CIM do AVE (Comunidade Intermunicipal do Ave), criada em 2009, onde pontificam dois concelhos dos mais industrializados da Região Norte: Guimarães e Vila Nova de Famalicão. Consequentemente, as conclusões extraídas do seu relatório de 2014 permitem atualizar (mesmo em contexto de crise económica) a região da Rota.

O Quadro 1 sugere-nos visitas desgarradas da Rota, ou seja, quem o faz, designadamente, as escolas, é com o sentido de um determinado local sem a contextualização da Rota: Central Hidroelétrica de Santa Rita, em Fafe; Curtumes, em Guimarães; Central do Ermal e Museu do Ouro de Travassos, 
Póvoa do Lanhoso; Antiga Estação de Comboios da Trofa, Trofa; Barragem de Guilhofrei, Vieira do Minho; Museu Ferroviário de Lousado (inaugurado em 2003, faz parte da Rota Europeia de Turismo Industrial desde 2007)

V. N. de Famalicão; Termas de Vizela, Vizela; Museu de Terras de Basto (ferroviário), Cabeceiras de Basto; e Museu Municipal de Mondim de Basto.

\subsection{A indústria ativa do Vale do Ave}

Pereira (s.d.) - com o apoio da ADRAVE -, propôs um cenário industrial: i) indústria têxtil e de vestuário (11 fábricas); ii) indústria do couro/calçado (seis unidades); iii) indústria automóvel (sete unidades); iv) indústria de equipamentos (sete unidades); v) indústria agroalimentar (duas unidades); vi) construção civil e obras públicas (três unidades); vii) indústria farmacêutica (uma unidade); viii) indústria de material de precisão (uma unidade); ix) indústria de material eletrónico (uma unidade); x) indústria metalomecânica (duas unidades); xi) indústria de plásticos (duas unidades); xii) indústria da siderurgia e metalurgia (uma unidade).

A atualização aproximada faz-se com dados de 2014, resultantes de um relatório da CIM do AVE (Comunidade Intermunicipal do Ave) formada em 2009 com oito municípios - seis dos quais coincidentes com os polos iniciais da Rota. É um panorama que importa realçar porque os equipamentos e as infraestruturas desativados aliam-se, na Rota, ao processo industrial ativo; uma conexão que, imbuída do espírito do turismo criativo (onde cabe o património industrial) induz uma forma aliciante e emergente no enquadramento dos destinos turísticos. Onde os serviços são relativamente menos importantes na estrutura económica do Ave, do que na do Norte, sendo a diferença ainda mais significativa quando a comparação é feita com o País como um todo (Silva, 2014: 125).

O Ave constitui um território com uma forte presença da indústria transformadora e uma relevante contribuição para o saldo exportador nacional. Esta característica torna-o numa região bastante produtiva, não obstante as elevadas taxas de desemprego, associadas à concorrência das economias emergentes que se têm vindo a especializar na produção competitiva e têm provocado o encerramento de_empresas, sujeitando ao desemprego um número significativamente elevado de trabalhadores. Entre 2007 e 2011, a indústria do Ave perdeu 15\% de empresas (11\% se apenas se considerarem as sociedades), $16,4 \%$ do pessoal ao serviço e 1,8\% do VAB (Valor Acrescentado Bruto). No entanto, a produtividade aparente do trabalho das empresas industriais do Ave aumentou 25\% entre 2007 e 2011 (Silva, 2014: 37; 117).

A contribuição dos vários concelhos para o VAB (Valor Acrescentado Bruto) das principais indústrias do Ave confirma a importância dos concelhos de Famalicão e Guimarães nas várias indústrias. A contribuição de Famalicão é dominante na fabricação de artigos de borracha (resultado da localização da Continental Mabor no município) e nas indústrias alimentares. No calçado, destaca-se o peso de Guimarães e, se bem que com menor expressão, de Vizela. As empresas sediadas em Guimarães são as principais contribuidoras para o VAB (Valor Acrescentado Bruto) dos produtos metálicos e fabricação de têxteis no Ave. O vestuário encontra-se mais disperso geograficamente: para além de Famalicão e Guimarães identificam-se as contribuições das empresas com sede em Fafe, Vizela e Póvoa de Lanhoso (Silva, 2014: 115-116).

Entre as empresas, com mais de 250 trabalhadores, o maior número corresponde a empresas têxteis de vários subsetores: preparação e fiação de fibras do tipo algodão (Têxtil Manuel Gonçalves); tecelagem de fio do tipo algodão (António de Almeida \&Filhos, Somelos, Têxtil J.F. Almeida,Armando da Silva Antunes e Teviz); tecelagem de fio do tipo seda e de outros têxteis (Riopele); branqueamento e tingimento (Pizarro); fabricação de artigos têxteis convencionados, exceto vestuário (Coindu, Lameirinho, Mundotêxtil, Coelima); fabricação de têxteis para uso técnico e industrial (TMG - Tecidos Plastificados, outros revestimentos indústria automóvel). No Vestuário são identificadas duas empresas de grande dimensão: Cofemel e Ricon Industrial. A fileira têxtil-vestuário está ainda representada nas empresas comerciais, com destaque para as empresas do grupo Salsa.

O calçado está representado pela Aco, Fortunato Frederico, Alberto Sousa e Campeão Português. Neste setor, o Ave destaca-se no total de Portugal, apresentando um peso superior à média, mas no Norte o seu peso é inferior à média, refletindo a importância de outros reconhecidos centros de produção de calçado. Exceto na fabricação de produtos metálicos, o Ave tem empresas com uma dimensão média, aferida em termos de emprego, superior à verificada no Norte e em Portugal. Na indústria de vestuário não se verificam diferenças significativas na dimensão das empresas (Silva, 2014: 115). 
$\mathrm{Na}$ lista de maiores empresas, apenas se identificaram três empresas industriais com capital estrangeiro. Para além da já referida Continental Mabor, contam-se a Leica-Aparelhos Ópticos de Precisão, S.A. e a Leonische Portugal, Lda, fabricante de cablagens e outro equipamento elétrico e eletrónico para veículos automóveis. Ambas são subsidiárias de multinacionais alemãs e estão no Ave desde 1973 e 1991, respetivamente. Alargando a pesquisa ao total de empresas registadas, podem identificar-se 17 empresas industriais com capital estrangeiro, num total de 62 empresas com capital estrangeiro. (Silva, 2014: 117)

No VAB de Famalicão destacam-se, como seria de esperar, os artigos de borracha e matérias plásticas. O vestuário é a principal indústria de Fafe e Póvoa de Lanhoso. Em Fafe, o têxtil e o calçado registam alguma importância, apresentando Póvoa de Lanhoso uma estrutura industrial menos diversificada. Finalmente, nos três concelhos mais orientais, o vestuário é uma presença relevante, exceto em Mondim, onde se destaca claramente o contributo das indústrias alimentares. Esta indústria é relevante também nos outros dois concelhos. Em quase todos os concelhos é registada a atividade no setor dos produtos metálicos, setor em que predominam as empresas de menor dimensão (Silva, 2014: 124).

Em síntese: a relação do património industrial desativado com o ativo permite um alargamento de oportunidades para o turismo industrial e criativo.

\subsection{A requalificação da Rota}

A NP 4556/2017 - Norma de Qualidade do Turismo Industrial em Portugal - é um elemento a que a Rota em causa pode recorrer mais numa perpetiva de desburocratização que, propriamente, de reativação; esta pertencerá aos stakeholders que se unam para a sua concretização.

O património industrial do Vale do Ave não pode apenas basear-se no resíduo formado pelas estruturas desativadas, ou seja, estruturar-se unicamente sobre o que alguns designam de baldios patrimoniais, mas terá de se configurar como o retrato histórico de uma região industrial. O projeto da Rota é uma verdadeira teia a urdir, e já lá vai mais de década e meia.

Nesse sentido, vai-se ao encontro da elencagem oficial do património industrial (Vieira e Lacerda, 2010: 9-10): a) O universo de estudo do património industrial é formado pelos bens imóveis e móveis integrados ou deslocados, os bens arquivísticos, iconográficos, fotográficos, fonográficos ou cinematográficos associados ou produzidos direta ou indiretamente no seio da empresa, como expressão estrutural da industrialização. É nesta interacção da diferente documentação que se obtém o entendimento global do património industrial, vivificando os valores culturais a transmitir às gerações seguintes. b) O património industrial integra, igualmente, edificações isoladas, conjuntos ou sítios, definidos pelos diversos programas construtivos ou pelas diferentes funções em articulação com o território, incorpora uma arquitetura, um urbanismo e uma paisagem de cariz industrial. c) O património industrial retém para as gerações futuras as mudanças operadas ao nível do saber-fazer, da ciência, da mecânica e do automatismo indissociáveis de uma reestruturação económica, social, cultural e técnica, fazendo avançar as mentalidades do seu tempo.

A Rota ganhará espaço com a importância de Guimarães e o seu valioso património histórico e cultural, com a arquitetura dos brasileiros em Fafe, entre outros (na linha de um turismo de memória dos descendentes no Brasil) e a sua inserção em roteiros europeus (Alves, 2004: 253). Em termos de balanço, basta perceber o que se afirma num artigo do Diário do Minho (2009-06-09), sete anos após o lançamento da Rota: Vale do Ave deve dinamizar a Rota do património industrial. i) Para um vereador da Câmara Municipal de Vila Nova de Famalicão "não se pode dizer que foi bem sucedido [o projeto da Rota]; ii) precisa de uma revolução; iii) os locais de interesse turístico não podem estar ao abandono $e$ de portas fechadas." A ADRAVE, promotora do projeto, limitou-se a reafirmar apenas o seu interesse no projeto.

Em termos de propostas: i). É imperioso dar vida à Rota e subrotas, aproveitando a NP 4556/2017 - Norma de Qualidade do Turismo Industrial em Portugal, como linha orientadora burocrática. ii) A requalificação terá como base os processos que exigem o ancoramento em autarquias, empresas, associações empresariais, associações culturais, museus e histórias empresariais, ensino superior (Universidadse do Minho e do Porto, Instituto de Estudos Superiores de Fafe), TPNP - Turismo do Porto e Norte de Portugal) para que possam funcionar como polos de uma rede vasta, criando-se formas de participação e vínculos sociais dos diversos tipos de agentes; arqueólogos, museólogos, historiadores, historiadores da arte, geógrafos, sociólogos, antropólogos, técnicos de planeamento turístico e industrial, técnicos ferroviários, técnicos de hotelaria, de restauração e animação socio- 
cultural, engenheiros, arquitetos... formarão equipas cruciais para levarem a cabo a requalificação, contando com as populações locais; iii) Encontrar uma entidade que centralize toda a dinâmica da rota; Guimarães tem condições para o efeito, mas o município já se comprometeu com Guimarães Marca; tal não obsta a que seja uma entidade semelhante à Rota do Românico do Sousa, Tâmega e Douro, com recurso a fundos comunitários, designadamente o Programa 2020. iv) Teremos uma fonte de rendimento económico (geradores de divisas, de emprego, de novos bens e serviços turísticos, bem como o dinamismo do comércio e serviços já existentes) associada à memória dos tempos, à identidade, e os cidadãos mais empenhados no conhecimento do território, do homem, das atividades e das instituições - fatores decisivos para a criatividade e a inovação tão preciosos à atualidade e ao futuro. O turismo vive das especificidades, uma vez que as pessoas se deslocam em busca do novo, do inusitado, da aventura, de um lugar caracterizado pela sua força identitária. v) O potencial do nicho turístico em estudo pode, de igual modo, ser maximizado se se promover a criação de redes com outras regiões nacionais e, ou, transnacionais. vi) Desta forma, ficam cobertos os sítios, as fábricas desativadas, as fábricas em ativo, as subrotas, os museus

\section{Conclusões}

A reativação e, ou, reorganização, da Rota do Património Industrial do Vale do Ave proporciona a recuperação da "estética da desindustrialização"; a museologia industrial permite o uso de numerosas chaves temáticas (arqueológica, técnica, socioeconómica, produtiva,,,), apresentando um carácter didático mais motivador que o tradicional (com as novas tecnologias). Uma entidade responsável pela gestão da Rota é crucial para o sucesso desta árdua tarefa sob o diálogo permanente com técnicos distintos, autarquias, empresários, entidades culturais e turísticas, ensino superior e populações locais acolherão oportunidades de recurso a apoios comunitários. O exemplo de sucesso da Rota do Românico do Sousa e Tâmega e Douro (norte de Portugal) é, forçosamente, motivador para o alcance do projeto.

A identidade cultural e sociológica portuguesa revê-se em exemplos de êxito de turismo industrial: o Museu do Pão, em Seia, que contrapõe a uniformidade industrializada da panificação à memória das extintas formas de moer, com multidões saudosas de sabores e odores, invadindo um espaço que ainda há pouco era o seu presente; S. João da Madeira é outro caso de excelente desenvolvimento do património industrial correlacionado com o turismo (circuitos e fábricas a visitar), espaço educativo (do 1. ${ }^{\circ}$ ciclo ao superior e grupos seniores); o Grupo Continente homenageia, no seu espaço comercial, a indústria sanjoanense (Fig. 3).

Os objetivos traçados - i) reconhecer o turismo industrial como uma nova tendência na Europa, particularmente, e em Portugal; ii) avaliar o seu potencial económico-social; iii) legitimar o planeamento em turismo industrial como um elo a estabelecer com as necessidades da população local; iv) relevar a ausência de dinâmica na Rota do Património Industrial do Vale do Ave criada em 2002 - conciliam-se com o desenho do nosso estudo, que merecerá um aprofundamento, com o intuito de pugnar, junto das entidades ligadas inicialmente ao projeto, e outras aderentes, por uma atitude de revalorização da Rota.

Figura 3: Chapelaria e calçado em S. João da Madeira
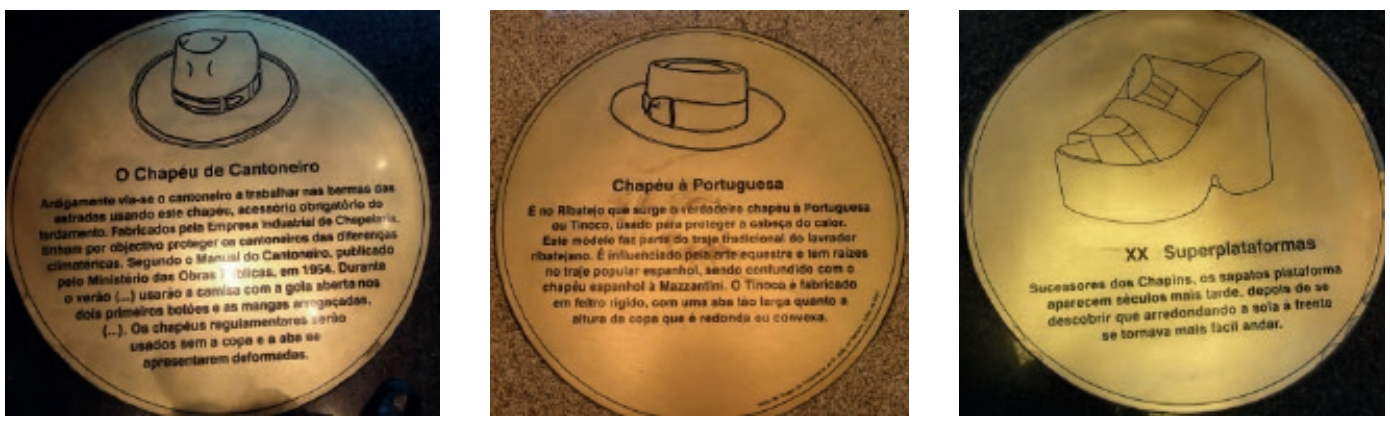

Fonte: Arquivo próprio 


\section{Bibliografia}

Abad, C. J. P. 2004. "La reutilización del patrimonio industrial como recurso turístico. Aproximación geográfica al turismo industrial". In: Treballs de la Societat Catalana de Geografia. Catalunha. Universidad Nacional de Educación a Distancia, 57, (7-32). Disponível em:<https://www.amazon. co.uk/Turismo-patrimonio-industrial-Gestión-turística ebook/dp/B00KYS34K6>. Acesso em 12 de junho de 2018.

Álvarez, N. G. 2017. "La musealizacion del Patrimonio Industrial. Dos modelos de intervencion en la provincia deHuelva: Casa Direccion en Valverde del Camino y Molino de Mareas "El Pintado" en Ayamonte". Pasos. Revista de Turismo e Património Cultural, vol. 15, n. ${ }^{\circ}$ 3, (859-672). Espanha: Universidad de Sevilla.

Alves, J. F. 2004. "Património industrial, educação e investigação: a propósito da Rota do Património Industrial do Vale do Ave". Revista da Faculdade de Letras: História, III série, vol. 5, (251-256). Porto: Faculdade de Letras da Universidade do Porto. Disponivel em: <http://hdl.handle.net/10216/7772>. Acesso em 03 de julho de 2017.

Alves, J. F. 2002. "A Indústria Têxtil do Vale do Ave”. In: Mendes, José Amado; Fernandes, Isabel (Coord.) - Património e Indústria no Vale do Ave (372-389). Vila Nova de Famalicão: Adrave.

Associação Portuguesa para o Património Industrial. Disponível em: <http://www.museudaindustriatextil. org/appi/patrimonio-nacional.php>. Acesso em 10 de setembro de 2014.

Associação Portuguesa para o Património Industrial. Disponível em: < http://www.museudaindustriatextil. org/appi/patrimonio-nacional.php>. Acesso em 10 de setembro de 2014.

Central de Reservas da Europa. Disponível em: < http:www.xatic.cat.>. Acesso em 15 de julho de 2014.

Cleto, J. \& Faro, S. 2002. "A Rota do Património Industrial do Vale do Ave: caracterização e breves considerações". ADRAVE, Património e Indústria no Vale do Ave. Um passado com futuro (148-153). Famalicão: ADRAVE.

Coit, J. C. L. 1999. "Patrimonio industrial y património de la humanidade. El ejemplo de las colonias textiles catalanas. Potencialidades turísticas y algumas reflexiones". Boletin de la A.G.E., n. ${ }^{\circ} 28$, (147-160). Barcelona: Universidad Autónoma de Barcelona.

Cordeiro, J. 2017. "A Norma de qualidade e os desafios que se colocam ao turismo industrial". Dos Algarves: A Multidisciplinary e-Journal, 30, 6-17. doi: 0.18089/DAMeJ.2017.30.1

Cordeiro, J. 2014.05.29. "Redes Europeias de Turismo Industrial". Seminário Desenvolvimento sustentável do turismo no Porto e Norte de Portugal. Fafe: Auditório do IESF. (Comunicação).

Costa, F. S. 2010 (maio). "Geopatrimónio ligado à agua. O caso do património industrial na bacia hidrográfica do rio Ave". VI Seminário Latino-Americano de Geografia Física II Seminário Ibero-Americano de Geografia Física. Coimbra. Universidade de Coimbra. (Comunicação).

Diário do Minho. 2009-06-09. Disponível em: http://livrozilla.com/doc/872238/património-industrial-e-museologia-em-portugal>. Acesso em 30 de julho de 2014.

Diário de Notícias. 2018.04.05. Disponível em: https://www.dn.pt/lusa/interior/turismo-industrial-ja-tem-norma-de-qualidade-especifica-para-a-realidade-portuguesa-9236163.html. Acesso em 15 de junho de 2018.

Direção Geral do Património Cultural. Portugal. Património Industrial. Disponível em: <http://www. patrimoniocultural.pt/pt/patrimonio/itinerarios/industrial/>. Acesso em 02 de setembro de 2014.

Duarte. J. M. 2013.11.25. "Património Industrial. Memória do Trabalho Produtivo". In: Estudos do Património. Lisboa: Universidade Aberta. Disponível em: <http://estudospatrimonio.blogspot. pt/2013/11/patrimonio-industrial-memoria-do.html>. Acesso em 30 de julho de 2014.

European Route of Industrial Heritage. Disponível em: <www.erih.net>. Acesso em 23 de agosto de 2014.

Indústrias em atividade em Portugal. 2010. Disponível em:< http://www.rotanoave.com/Industria-em-Actividade.aspx>. Acesso em 25 de agosto de 2014.

Ironbridge. Disponível em:<http://www.english-heritage.org.uk/visit/places/iron-bridge/history/>. Acesso em 17 de junho de 2018.

Itinéraires et Paysages Culturels. Un Patrimoine Commun de l'Europe. Disponível em:<http://hdl. handle.net/10773/7812>. Acesso em 05 de setembro de 2014.

Itinerários Culturais do Conselho da Europa (Instituto Europeu dos Itinerários Culturais). Disponível em: <http://www.culture-routes.lu/php/fo_index.php?)>. Acesso em 05 de setembro de 2014.

Matos, A. C. e Sampaio, M. L. 2014. "Património Industrial e Museologia em Portugal". Revista Museologia \& Interdisciplinaridade, v. 3, nº 5 (95-112 (online ISSN 2238-5436). Disponível em:<http:// hdl.handle.net/10174/11102>. Acesso em 20 de junho de 2018. 
Matos, A. C., Ribeiro, I. M., Santos, M. L. 2003. "Intervir no património industrial: das experiências realizadas às novas perspetivas". Sampaio, Maria da Luz (ed.). Atas do Colóquio de Museologia Industrial. Reconversão e Musealização de Espaços Industriais, (21-32). Porto: Museu da Indústria. Disponível em: <http://hdl.handle.net/10174/10905>. Acesso em 15 de junho de 2018.

Mota, A. C. S. 2011. Turismo Industrial. Nova Força Económica para Municípios. Caso de Águeda. Dissertação de mestrado. Aveiro: Universidade de Aveiro. Disponível em: <http://instagram.com/ turismoindustrialsjm>. Acesso em 02 de setembro de 2014.

Pereira, V. B. (coordenador) (s.d.). Património Industrial do Vale do Ave. A Formação do Quotidiano Operário. Sociedade, Economia e Cultura num Contexto Industrializado do Vale do Ave. (Dos Anos 50 à Atualidade). Disponível em:<http://www.rotanoave.com/Estudo/index.html $>$. Acesso em 02 de setembro de 2014.

Prat, J. M. \& Valiente, G. C. 2012. "El patrimonio industrial como dinamizador del territorio. El caso del ecomuseo La Farinera, en Castelló d'Empúries (Cataluña)”. In: Documents d'Anàlisi Geogràfica, vol. 58/1 (79-100). Barcelona: Universitat Autònoma de Barcelona. Departament de Geografia. Disponível em: <http://dag.revista.uab.es/article/view/v58-n1-prat-canovas>. Acesso em 18 de junho de 2018.

Rota da Lã - Translana. Disponível em: http://www.centerofportugal.com/pt/a-rota-da-la-translana/. Acesso em 04 de setembro de 2014.

Rotas do volfrâmio na Europa. Memória dos homens e património industrial. Disponível em: <www. minhaterra.pt/rotas-do-volframio-na-europa-memoria-dos-homens-e-patrimonio-ndustrial.T11624. php>. Acesso em 02 de setembro de 2017.

RPI - Rota do Património do Vale do Ave. Disponível em: <http://www.rotanoave.com/rota-apresentacao. aspx>- Acesso em 02 de julho de 2014.

Rutas de la lana. Disponível em: <www.rutasdelalana.eu>. Acesso em 02 de setembro de 2014.

Silva, J. M. (coordenador). 2014.07.03. Plano Estratégico de Desenvolvimento Intermunicipal 2014-2020. Relatório final Comunidade Intermunicipal do Ave. Disponível em: <http://www.cim-ave.pt/index. php/quem-somos/municipios>. Acesso em 20 de agosto de 2017.

Turismo Industrial.cat. Disponível em: <http://www.xatic.cat>. Acesso em 10 de setembro de 2014.

Turismo de Portugal. Normas de Qualidade. Qualidade e Sustentabilidade. Disponível em: <http:// business.turismodeportugal.pt/pt/crescer/Qualidade\%20_Sustentabilidade/Paginas/normas-de-qualidade.aspx>. Acesso em 10 de junho de 2018.

UNESCO World Heritage Center. Disponível em: <http://whc.unesco.org/>. Acesso em 02 de setembro de 2014.

Vieira, J. Lacerda, M. (coor. de) 2010. Kits - Património | Património Industrial. Lisboa: IHRU / IGESPAR. Disponível em: <http://www.patrimoniocultural.gov.pt/static/data/ patrimonio_imovel/ inventario/kit01.pdf>. Acesso em 10 de setembro de 2014. 